\title{
3D Assessing Soft Skills in Students
}

\author{
Avdeeva A.P. Oreshkina O.A. Safonova Yu.A.*
}

Bauman Moscow State Technical University, Moscow 105005, Russia

Email: safonova@bmstu.ru

\begin{abstract}
Modern digital technologies are currently considered as technologies that can compensate for disabilities and contribute to educational and professional inclusion. At the same time, a person's success in the profession is determined by the level of development of a number of professional and meta-subject competencies (soft skills) that are in complex interactions. In case of any restrictions on the state of health, person should be able to build his life and professional path taking his/her restrictions into account - to be able to minimize barriers by oneself, apply technical and auxiliary tools, etc., to compensate for the restrictions. We are talking about rehabilitation competencies, which we consider as the basis and conditions for developing soft skills. This determined the relevance of developing the methodological foundations of a database for assessing and accounting for these competencies in the process of professional training at a university. A 3D assessment of the competencies in students with disabilities is developed at Bauman Moscow State Technical University (BMSTU) on the basis of many years' experience of working with hearing impaired students: teaching fundamental, socio-humanitarian and rehabilitation disciplines; counselling on issues of socio-psychological and professional adaptation. The main parameters of assessing are super subject competencies: learning skills, social development skills and social interaction skills. Such a voluminous assessment provides a complete picture from the point of view of the manifestation of the totality of these competencies in the professional environment, designates areas that require development and additional measures (educational, rehabilitation). This technology in educational process allows not only to evaluate skills acquired by student, but also to identify specific problems in student while acquiring certain skills (competencies), to draw up a plan to solving them and implement it.

The proposed approach can be applied not only for developing a database for assessing competencies in hearing impaired students, but also for all students who need in facilitating adaptation to the university and profession. This is especially true for students with communication problems including foreigners, migrants.

Keywords: inclusive education, meta-subject competencies, soft skills, students with special needs, $3 D$
\end{abstract}

assessment

\section{INTRODUCTION}

The problem of assessing meta-subject competencies (soft skills) acquires a special status in the format of inclusive higher education. Ensuring equal opportunities in education requires not only the creation of an accessible environment in the university, but also the development of soft skills in students with special needs that ensure the success of their social adaptation, professional formation and personal development $[1,2]$.

Monitoring and self-monitoring of these compensations in students at the university is an important condition for building an individual educational and professional trajectory. The technology of systematic assessment of the soft skills in university students is not just a new tool, but also little studied and tested in Russian practice. The $3 \mathrm{D}$ assessment model is a modern innovative educational technology. It allows not only to identify problem areas of students' personal and professional development, but also to develop individual trajectories of their development on this basis [3-6].

Purpose of work: presentation of the developed model of 3D assessing meta-subject competencies in hearing impaired students.

\section{METHODOLOGY}

Meta-subject competencies in students with hearing impairments are presented in three main spaces of an inclusive educational environment: learning activity, social development and social interaction. Their holistic unity determines the integrated nature of meta-subject competencies in students with special needs. The interconnection of these three groups of soft skills: learning capability, social development and social 
interaction characterize students' behavior in an inclusive university environment.

To develop soft skills in students with special needs, information and communication support of their education process is being used. Information and communication technologies form and develop students' skills of independent work with electronic resources, virtual learning activities as a member of a distributed user's community [7, 8]. Such environment is a tool for creating a comprehensive system to support students with special needs in practices of cooperation and make them flexible in changing their needs and behavior [9].

Development of communication skills in students is being facilitated by preparing Power Point presentations by students themselves. Presentations are also being used to implement the scenario of "inverted" learning. The next method used is the glossary. Work with dictionaries carries out in real time, using Internet dictionaries. In some cases, the Google- or Yandex- picture' function can help. The correct choice from possible variants of interpreting terms by hard-of-hearing students controls by the teacher. Preliminary compilation of the glossary does not carry out, as vocabulary spaces are individual in students. In addition to, when addressing to a dictionary to exclude misunderstanding the semantic meaning of the word in a particular situation, the word uses in the context. The most important terms unknown to students should be written on the board with explanation. At the end of studied course, the student has his/her own individual glossary.

We consider the use of a smartphone to remove communication barriers in absence specially equipped audience as a necessary element of a learning session with hearing impaired students. This simulates a business communication situation when there is no specially equipped classroom at hand.

Using the potential of social networks in extracurricular activities is very important for the formation of communication skills. Social networks stimulate a contact activity of students with disabilities, allow them to exchange opinions and consult on important professional and life connected issues in the "support" group, as well as act as consultants. Practice has shown that it is important to form purposefully such a networks which include graduates with special needs, rehabilitation therapists (consultants), and potential employers.

To form social development skills, student use online testing with subsequent self-analysis of his/her strengths and weaknesses and identifying his/her development zones; personal consultation with a psychologist is carried out. Such form of work implies preliminary selecting those test material by the teacher in the Internet that is adequate to the communicative abilities in students with hearing impairments, as well as coordinating self-testing process in the classroom and assistance in analyzing results.

We use You-tube and other video resources to select popular science films and short fragments from feature films (10-15 minutes) that illustrate typical communicative barriers. Viewing them through a projector or smartphone activates interest to the topic of classes in students. An important selection criterion is the presence of subtitles.
Watching video materials is a very important activity for forming social development skills in students with hearing impairments.

To monitor developing soft skills in students with special needs it is possible to use a special network platform, which consists of an information part and a diagnostic one. The information part («Electronic University») contains the information on the implementation of the inclusive educational process: schedule of classes and consultations, students' academic performance, special events, trainings, meetings with graduates, etc. The diagnostic part («Career portfolio») contains a database for assessing soft skills and a trajectory of individual development as well [10].

\section{THE RESULTS OF THE STUDY}

The developed model of 3D assessing meta-subject competencies in students with hearing impairments is presented in Fig. 1.

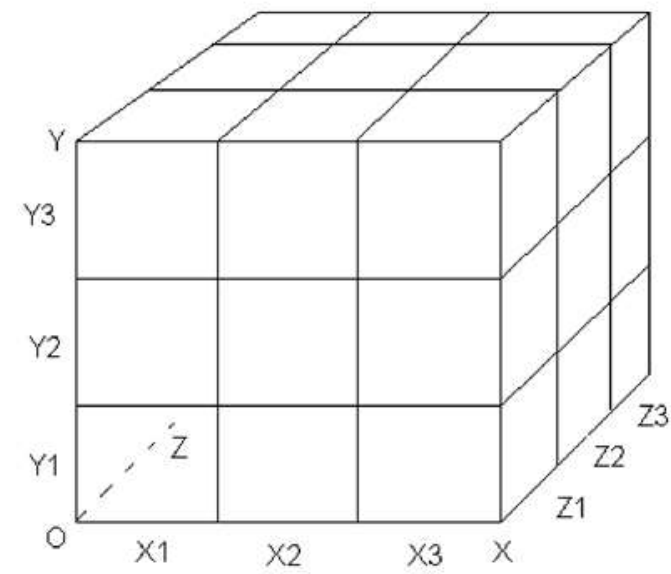

Figure $13 \mathrm{D}$ model of assessing meta-subject competencies in students

The content of the complex of scientific and social development of the individual at the university includes the processes of involvement in educational and scientificcognitive activities, ways to enter the collectives designed for the cognitive growth of the individual, mechanisms of social positioning, etc.[11].

In the 3D model of meta-subject competencies in students with hearing impairments learning skills, social development skills and social interaction skills are being evaluated.

On the OX axis learning ability is represented by following grades: $\mathrm{X} 1$ is learning activity motivation; $\mathrm{X} 2$ is an academic performance in academic disciplines; $\mathrm{X} 3$ is a sustainable skill of study activity.

On the OY axis social development as forming a positive social identity based on the displacement of the role of the "disabled person" from structure of identity is represented. This parameter includes following: Y1 is adopting values and norms of an inclusive educational 
communication; Z3 is a sustainable skill of interpersonal communication. Indicators of soft skills' development in students include motivational, cognitive and behavioral characteristics (Table 1) environment; Y2 is knowledge of his/her capabilities and limitations; Y3 is a sustainable skill of the personal development.

On OZ axis a social interaction is represented by following estimates: $\mathrm{Z} 1$ is a focus on social interaction; $\mathrm{Z} 2$ is understanding of the features of interpersonal

Table 1 Indicators of the development of soft skills in students

\begin{tabular}{|c|c|c|}
\hline Motivational indicators & Cognitive indicators & Behavioral indicators \\
\hline$X 1, Y 1, Z 1$ & $X 2, Y 2, Z 2$ & X3, Y3, Z 3 \\
\hline $\begin{array}{c}\text { Interest towards learning } \\
\text { activities }\end{array}$ & $\begin{array}{l}\text { Academic performance - grades, } \\
\text { completion of training tasks on time }\end{array}$ & $\begin{array}{l}\text { Attendance of consultations, the } \\
\text { skill of independent work on } \\
\text { training tasks }\end{array}$ \\
\hline $\begin{array}{l}\text { Adoption of values and } \\
\text { norms of an inclusive } \\
\text { educational environment }\end{array}$ & $\begin{array}{l}\text { Knowledge of his/her capabilities } \\
\text { and limitations }\end{array}$ & $\begin{array}{c}\text { Skills of oral and written } \\
\text { communication; } \\
\text { Skill in applying technical means } \\
\text { to minimize barriers }\end{array}$ \\
\hline $\begin{array}{l}\text { A focus on social interaction } \\
\text { with the priorities of the } \\
\text { integrated environment }\end{array}$ & $\begin{array}{l}\text { Understanding peculiarities of } \\
\text { interpersonal communication }\end{array}$ & $\begin{array}{l}\text { Style of interpersonal } \\
\text { communication }\end{array}$ \\
\hline
\end{tabular}

A group of experts is carrying out an assessment of the development level of meta-subject competencies in students. The expert group includes teachers of educational disciplines, tutors, a psychologist and curators. Assessment of forming meta-subject competencies in students is being based on the frequency of manifestation of this indicator in various situations: how often or rarely this indicator appears as well as on the breadth of situations' outreach: what is the range of manifestations of indicator in learning and extra-learning situations.

\section{THE DISCUSSION OF THE RESULTS}

Based on the processing of expert survey data, a profile of super-subject competencies is being built which is including motivational, cognitive and behavioral indicators.

Motivational indicators characterize interest towards educational activities, the adoption of values, norms of an inclusive educational environment and focus on social interaction.

If a student has a high level of motivational indicators, he/she is satisfied with professional choice and study at the university, carries out educational tasks with interest in the classroom, focuses on personal and professional development, is interested in enhancing his/her social and professional competence. Such students create an atmosphere of friendliness and openness in the group, offer help and assistance to other students. They actively collaborates with other students, builds relationships in a group based on mutual respect and trust. Students with high level of motivational indicators focus on achieving common goals when doing group exercises; observe norms and requirements of the organizational culture of the department and university. Such students are aimed at expanding their social ties. They demonstrate belonging to the cultural community of the university' students, reject the social role of "disabled person".

At a low level of motivational indicator in students, we observe the following: such students are not satisfied with their specialty and are disappointed with their professional choice. They are not focused on work in the engineering field, would like to change their specialty and are not interested in learning. These students prefer to work alone, do not show an interest to cooperation with other members of their group, do not help other students and focuses strongly on their own interests. They do not seek to achieve common goals while doing any group work; do not observe norms and requirements of the organizational culture of the department and university. Such students are not targeting at expanding social ties; they demonstrate and defend a culture of the deaf community.

Cognitive indicators reflect academic performance in academic disciplines, knowledge of his/her capabilities and limitations, understanding of characteristics of interpersonal communication.

With a high level of cognitive development, the student has positive self-assessment; he/she performs educational tasks on time and has no debts. The student adequately evaluates himself, knows his strengths and weaknesses and understands well how to behave in different social situations, with different people. 
At low indicators' rates, such a student does not have time for a number of subjects, has debts, does not cope with the curriculum, has inadequate self-esteem and does not understand the rules and specifics of interpersonal communication in an integrated environment.

Behavioral indicators reflect the characteristics of behavior and activities in the inclusive educational environment of the university.

Having the high level, the student has good working capacity when performing learning tasks; he/she attends consultations and asks questions, he/she is able to complete tasks independently. Such a student is independently able to acquire the knowledge and skills necessary for professional activities and interaction in the socio-professional environment. $\mathrm{He} / \mathrm{she}$ participates in the scientific or social activities of his/her department; has good skills in oral and written communication, can apply technical facilities to minimize free barriers. $\mathrm{He} / \mathrm{she}$ demonstrates confident behavior, is able to influence the opinion of group members, takes initiative in communication, is able to listen to an interlocutor, understands him and communicates freely in an integrated environment.

The low level is being manifested in following: a student is constantly distracted when completing educational tasks, absent-minded. Such student keeps silence, does not focus on learning process, does not ask questions, finds it difficult to answer posed questions; does not attend consultations, feels difficulties in educational activities. $\mathrm{He} /$ she does not know how to work upon himself and needs constant control; has poorly developed oral and written communication skills as well as skills to apply technical facilities to minimize environmental barriers. Such a student does not show initiative in communication, is not capable and does not try to understand other students, expresses his/her thoughts not clearly, does not know how to listen to the interlocutor, interrupts him.

The most important final stage of the assessment is the analysis of the dynamics of development of meta-subject competencies. Evaluation results are being discussed with teachers, curators and tutors. It is very important to bring to students' notice indicators of the profile of soft skills, mark achievements, identify and discuss the causes of difficulties, problems, and discuss directions for the further development of these competencies.

\section{CONCLUSION}

The presented 3D model for assessing meta-subject competencies is a technology for a comprehensive assessment of developing soft skills in students with special needs. This technology in educational activities allows not only to assess the level of skills' development, but also to answer the question what is specific problem (problems) in student from the point of view of mastering certain skills and / or competencies, draw up a plan to correct these individual deviations and implement it. Thus, the developed model of soft skills assessment is the technology for diagnosing personal and professional becoming in a university, identifying problem areas in this process and building an individual development path for students with special needs. The offered approach can be applied not only to develop a database for assessing soft skills in students with special needs, but also for students who need to facilitate their adaptation in the university and profession. This is especially true for students with communication problems, including foreign students and migrants.

\section{REFERENCES}

[1] A.V. Khutorsky, Intersubject approach in learning. Scientific and methodological manual, "Eidos" Publishing House, Publishing House of the Institute of Human Education, Moscow, 2012. 73 p.

[2] Anna Avdeeva, Nadezhda Bagdasaryan, Yulia Safonova, Way to yourself: a model of professional realization of hearing impaired students, Proceedings of the 4th International Conference on Contemporary Education, Social Sciences and Humanities (ICCESSH 2019), Advances in Social Science, Education and Humanities Research, vol.329, Atlantis Press, Moscow, 2019, p.660-664. DOI: https://doi.org/10.2991/iccessh19.2019.147

[3] Andrey Andrunik, Vadim Cherdantsev, 3D-model of personnel innovative competences of self-developng, self-organizing systems, Proceedings of the 2nd International Conference Innovation Management and Company Sustainability, Vysoká škola ekonomická v Praze, nakladatelství oeconomica, Praha, 2014.

[4] A. Andrunik, Designing a 3D model of staff behavior self-organizing, self-developing systems based on diagnostics of Competencies, Scientific and methodological electronic journal "Concept", vol. 13, 2015, pp. 1481-1485. URL: http://ekoncept.ru/2015/85297.htm (access date: 03.10.2020).

[5] V.V. Ivin, K.V. Ivina, 3D-assessment: features and prospects of use, Proceedings of International Scientific-Practice Conference Innovative technologies in education and science, CSC Interactive Plus, Cheboksari, 2017, pp.92-98., 2017. DOI: 10.21661/r280859

[6] P.S. Nosov, V.M. Tonkonogiy. 3D assessment of student learning paths, Trudi Odesskogo politehnicheskogo universiteta [Proceedings of Odessa Polytechnic University] 2(28), 2007, pp.129-131.

[7] A.P. Avdeeva., O.A. Oreshkina, Yu. A. Safonova, Formation of intersubject competencies of hearingimpaired students on the basis of information and 
communication technologies, Proceedings of the 1 st International Scientific Conference Modern Management Trends and the Digital Economy: from Regional Development to Global Economic Growth, Advances in Economics, Business and Management Research, vol. 81, Atlantis Press. Yekaterinburg, 2019, pp. 662-666. 2019. DOI: https://doi.org/10.2991/mtde19.2019 .134

[8] O.A. Oreshkina, A.A. Gourov, Solving the problem of limited content accessibility in natural science disciplines for students with hearing impairments in technical university, Proceedings of IEEE Global Engineering Education (EDUCON), Dubai, United Arab Emirates, 2019, pp. 350-351, Art. no 8725219. DOI: 10.1109/EDUCON.2019.8725219

[9] A.O. Karpov, Dissonance tolerance as a new principle of the cross-cultural sustainability, Proceedings of 7 th International Conference on Intercultural Education Education, Health and ICT for a Transcultural World, EDUHEM, Procedia Social and Behavioral Sciences, vol. 237, In Soriano, E., Sleeter, C. (eds.), Almeria, Spain, 2016, pp. 723-730, 2017. DOI: $10.1016 /$ j.sbspro.2017.02.113

[10] A.P. Avdeeva, O.A. Oreshkina, Yu.A. Safonova, Career counseling for hearing impaired people using information technology, Proceedings of the I International Scientific and Practical Conference on Digital Economy, ISCDE, Advances in Economics, Business and Management», vol.105, Atlantis Press, 2019, p.666-671. DOI: https://doi.org/10.2991/iscde19.2019 .129

[11] A.O. Karpov, Universities in knowledge society: Theory of creative spaces, Voprocy filosofii, no1., 2018, pp.17-29. 